\title{
El poder del lugar y su potencial político en la legitimación de la(s) memoria(s) del conflicto político armado*
}

The power of the place and its political potential in legitimizing the memory(ies) of the armed political conflict

0 poder do lugar e seu potencial político na legitimação da(s) memória(s) do conflito político armado

Fecha de entrega: 30 de agosto de 2012

Fecha de evaluación: 31 de octubre de 2012

Fecha de aprobación: 6 de diciembre de 2012

Elsa Blair Trujillo ${ }^{* *}$

\section{Resumen}

El artículo apunta a desarrollar una reflexión sobre el tema de las memorias del conflicto político armado y/o de la guerra, que podría contribuir a potenciar políticamente los esfuerzos y las iniciativas de muchas organizaciones de víctimas en el país. En las propuestas que viene haciendo la geopolítica crítica en el marco de discusiones del

* El presente artículo está vinculado a los estudios que la autora realiza sobre la sociología de la violencia.

* Doctora en Sociología de la Universidad Católica de Lovaina. Magíster en Investigación Social y licenciada en Sociología de la Universidad de Antioquia. En esta institución trabaja como docente de posgrados en el programa de Sociologia, especificamente en lo relacionado con la temática de la violencia y su relación con la ciencia sociológica. Es investigadora de tiempo completo en la Universidad de Antioquia. Correo electrónico: eblair@iner.udea.edu.com 
pensamiento social contemporáneo, específicamente en lo referente a la importancia del espacio en los procesos sociales y políticos -lo que, de paso, cuestiona la concepción estadocéntrica del poder-, se le confiere una enorme fuerza política a otros espacios y lugares, más cercanos a los sujetos que, como las víctimas, habitan lugares y espacios más micro y cotidianos.

Palabras clave: memoria, espacio, lugar, víctimas, geopolítica crítica.

\section{Abstract}

This article points for a reflection on the issue of memories of the armed political conflict and/or war, which could contribute to politically boost the efforts and initiatives of many organizations of victims in the country. In the proposals being made by critical geopolitics in the framework of discussions on contemporary social thinking, specifically regarding the importance of space in social and political processes -which, by the way, questions the state-centered power conception-, confers an enormous political force to other spaces and places, closer to the individuals that, like the victims, live in more micro and everyday places and spaces.

Keywords: memory, space, place, victims, critical geopolitics.

\section{Resumo}

O artigo aponta a desenvolver uma reflexão sobre o tema das memórias do conflito político armado e/ou da guerra, o que poderia ajudar a impulsionar os esforços e as iniciativas de muitas organizações de vítimas no país. Nas propostas que vem fazendo a geopolítica critica no marco das discussões do pensamento social contemporâneo, especificamente no referente à importância do espaço nos processos sociais e políticos -o que, de fato, questiona a concepção estado céntrica do poder-, confere-se lhe uma enorme força política para outros espaços e lugares, mais perto para os sujeitos que, como as vítimas, habitam lugares e espaços mas pequenos e cotidianos.

Palavras-chave: memória, espaço, lugar, as vítimas, geopolítica crítica. 
Lo que no se puede es callar. Reyes Mate

Vuelvo a experimentar que el espacio da un conocimiento que no da el tiempo.

Es de otro orden.

Lo sientes cuando recorres el camino.

Reyes Mate

\section{A modo de introducción}

En el país, el tema de la(s) memoria(s) del conflicto armado y/o de la guerra sigue a la orden del día en la agenda política y académica. Se continúa debatiendo sobre la posibilidad de hacer memoria en una situación un tanto sui géneris, como la coyuntura colombiana de "no-posconflicto". Las apuestas e iniciativas de reconstrucción de las memorias del conflicto por parte de diversas organizaciones de víctimas, tanto en comunidades rurales como urbanas, no dejan de ser arriesgadas y peligrosas. Con todo, tanto quienes promueven estas iniciativas como las organizaciones que las acompañan no quieren desistir de la tarea, en la medida que ella apunta a la dignificación de las víctimas que han vivido tanto dolor y tanta muerte en medio del conflicto. Algunas de ellas, las más atrevidas, no solo insisten en el desarrollo de ejercicios de memoria que permitan poner en palabras los hechos dolorosos que han vivido, contribuyendo así a la reparación emocional de las víctimas, sino también en potenciar políticamente estas experiencias y lograr recuperar, entonces, el sentido político de la dignidad (Carrizosa, 2010; Blair, 2011a, 2011b.).

Como una contribución a la posibilidad de potenciar políticamente estas memorias de dolor, este artículo quiere desarrollar una reflexión en torno al poder del lugar (Agnew, 2005; Piazzini, 2006), gestado en el marco del debate sobre la(s) geopolítica(s) crítica(s). El tema tiene una amplia discusión en el terreno de las geografías contemporáneas o incluso en los estudios socioespaciales, que vienen reivindicando el papel tan importante que tiene el espacio en la producción y reproducción de los fenómenos sociales y políticos. Ello ha permito hacer visible, contrario a lo que se ha creído por largo tiempo en las ciencias sociales, que el espacio no es una dimensión meramente geofísica (algo así como el escenario físico e inmovible, un "contenedor" sobre el cual se desarrollaría la vida social), sino una producción social cuya dimensión simbólica y política incide profundamente en esos procesos. 
Igualmente, este nuevo campo de reflexiones evidencia la importancia de lo que se ha considerado el primado del tiempo sobre el espacio (Piazzini, 2006, p. 55) y los intentos por "equilibrar" esas dos dimensiones de la vida social. En efecto, espaciotiempo, en el caso de las teorías sociales, implica un encuentro entre repertorios conceptuales cuya trayectoria de relacionamiento ha sido débil e inequitativa: una prolongada tradición del tiempo como condición de la existencia, núcleo de la historia, estructurante de la memoria, para ponerla en contacto con un espacio que ha sido tradicionalmente minimizado por la filosofía, sobredeterminado por la historia y tratado en las ciencias, sociales como una cuestión meramente metodológica o de escalas (Piazzini, 2006, p. 55).

Incluso con esos avances en la discusión, su reflexión es escasa en la literatura sobre las memorias del conflicto. Al parecer, no hemos valorado, en su justa medida, lo que las apuestas por una nueva concepción espacial -que riñe con la geopolítica en su forma más clásica- podría aportar a muchos fenómenos sociales y políticos, entre ellos el tema de la(s) memoria(s) del conflicto. Sin duda, su tesis central, que cuestiona la concepción estadocéntrica del poder para mostrar que existen otras formas de espacialización de este, otorga un rol muy importante a otras espacialidades, como la del lugar (no solo la espacialidad del Estado); en consecuencia, muestra el potencial que tendrían las experiencias de memorias que se viene haciendo a nivel local o en espacios más micro, donde se resuelve el día a día de estas poblaciones; al potenciarlos como espacios de poder, las comunidades no tendrían necesidad de abogar por un reconocimiento y una legitimidad del orden estatal, sino más micro.

\section{Una mirada a la espacialidad para pensar el lugar}

Las espacialidades, como es apenas obvio, están ligadas a lugares y/o territorios; sin embargo, no son, como solemos entender, un asunto meramente físico o geofísico referido a los lugares como materialidades. Estos últimos son solo un componente de la espacialidad que se estructura en la interacción de componentes físicos, pero también político-estratégicos y simbólicos (Agnew, 2005; Cairo, 2006).

Sin duda, no es para nada fácil cambiar el lugar de interrogación del espacio, como lo viene proponiendo la geopolítica crítica. Y no es fácil, en parte, porque ello modificaría sustancialmente las maneras como hemos venido pensando el espacio tradicionalmente, esto es, se modificarían nuestros esquemas o hábitos de 
pensamiento; y tampoco es fácil porque las ciencias sociales no tienen un desarrollo muy consistente, desde lo teórico, sobre lo espacial (Bolívar, 2006). La mirada meramente física que comúnmente le damos al espacio, particularmente desde las ciencias sociales, es la consecuencia de un cierto descuido del espacio en esas disciplinas (Wallerstein y Balibar, 1996, citados en Bolívar, 2006).

Habría, pues, según estos autores, una tendencia a ignorar la geografía y la dimensión espacial de la existencia social. En algunos casos, vemos al espacio como un "escenario" o "plataforma" donde se suceden los procesos sociales ( $\sin$ mayor interés teórico); en otros casos, el espacio aparece como un elemento del "contexto", pero con una influencia menor en el desarrollo de la vida social. Estas apreciaciones del espacio como plataforma o como contexto tienden a negar un lugar analítico específico de lo espacial y a asumir que las relaciones sociales transcurren en un espacio abierto, yermo e incluso vacío (Bolívar, 2006, p. 120).

A su vez, y dado que en las ciencias sociales y humanas predomina una mirada demasiado institucional de lo político, cuando se trata de darle dimensión política al espacio, se le asocia al Estado o a lo estatal. El espacio se definiría, así, por los límites territoriales del Estado - así se concibe en la mayoría de los análisis—, terminando por asumirse que "el espacio de la vida social por excelencia es el espacio del Estado y que este funciona como 'contenedor' de la interacción social” (Bolívar, 2006, p. 120). Esta concepción se basa, por tanto, en una "estatalización del espacio y del poder", asumiendo además al Estado como si fuera una forma "natural", desconociendo que los procesos que han contribuido a la formación de la forma Estado, en tanto organización socioespacial específica, es una forma histórica propia de los países europeos. Se desconoce también que existen otras formas de organización socioespacial $^{1} \mathrm{y}$, sobre todo, las relaciones de poder que subyacen a esas formas de organización socioespacial.

Las formas concretas de esta concepción responderían, pues, a un mero asunto de escalas que, partiendo de lo "nacional” como límite del Estado-nación, piensa lo ínter

1 Vale la pena resaltar, aunque no vayamos a desarrollar esta reflexión aqui, la similitud que tendria este cambio en la consideración de la espacialidad del poder con la apuesta analítica de Foucault, quien sostenía: "Creo que no existe un único poder en la sociedad, sino que existen relaciones de poder extraordinariamente numerosas, múltiples, en diferentes ámbitos, en los que unas se apoyan en otras y en las que unas se oponen a otras [...] Estas relaciones de poder son sutiles, se ejercen en niveles diferentes, y no podemos hablar de un poder, sino más bien describir relaciones de poder" (Foucault, 1999, pp. 277-278). 
o supranacional "desde fuera" y lo regional y local "desde dentro". Lo nacional o, más concretamente, "el espacio nacional” sería el que se tiene presente en el ejercicio político estatal: un espacio asumido como homogéneo, continuo y claramente diferenciable de otros espacios nacionales a través de las fronteras. En esta concepción se imagina el Estado como provisto de un espacio que le pertenece, sobre el cual debe desplegar su dominio, en el que están localizados los ciudadanos que representa " $y$ en donde ya no hay formas localizadas de dominación distintas a lo estatal" (Bolívar, 2006, pp. 121-122). Esto es así porque otras formas de organización espacial y de dominación se asumen como "inferiores” en relación con el Estado. Esta concepción del espacio, en su forma estatal y "naturalizada”, todavía subsiste en muchos de los análisis de lo espacial en las ciencias sociales y tiene una clara concreción en el análisis del conflicto político.

En efecto, hasta épocas muy recientes lo que ha sostenido, en términos espaciales, el análisis del "conflicto en Colombia es esta espacialidad asociada a la estatalidad (Blair, Pimienta y Agudelo, 2004). En otras palabras, las diversas disciplinas sociales que han abordado el tema del conflicto político en su dimensión territorial asumen la espacialidad exclusivamente en términos del Estado-nación, ignorando otras formas espaciales de organización del poder. El espacio se piensa, sobre todo en los análisis regionales del conflicto, asociado siempre a "escalas mayores" del orden de lo nacional. En estos términos, su dimensión política o, más bien, la espacialización del poder solo se construye en relación con un "centro" del orden de lo nacional.

Pero, ¿de qué estamos hablando cuando hablamos de "geopolítica clásica"2 y cómo ella es puesta en cuestión por la(s) geopolítica(s) crítica(s)? El término "geopolítica" se ha usado durante mucho tiempo para definir el estudio de las representaciones y prácticas geográficas que sustentan la política mundial. Una definición más concreta la asume como "el examen de los supuestos, clasificaciones y explicaciones geográficas que participan en el diseño de la política mundial" (Agnew, 2005, p. 6). Al utilizar esa definición, Agnew trata de explicitar de qué modo el descubrimiento y la integración del mundo en una sola entidad, por un lado, y el desarrollo del Estado territorial como ideal político, por el otro, se unieron para crear el contexto de la política mundial moderna. Esta última no fue inventada "hasta que fue posible ver el mundo ('en la

2 Esta geopolitica va a ser nombrada por Agnew como la "imaginación geopolítica moderna". Para diferenciar su propuesta se ha asumido el término "geopolítica" (Agnew, 2005, p. 6). 
imaginación') como un todo y plantearse objetivos relacionados con dicha escala geográfica” (Agnew, 2005, p. 6).

Según este sistema, se le dio prioridad a las escalas global y nacional por encima de las otras, las cuales, finalmente, se organizaron con soberanía absoluta sobre sus propios territorios, de acuerdo con el principio de soberanía de los Estados. Los problemas y las decisiones políticas han sido definidos según las escalas geográficas, mediante las cuales la mundial sería la superior en orden de importancia hacia las escalas inferiores. El término "geopolítica", por lo general, se suele aplicar a escala global, pero se basa en suposiciones sobre la diversa importancia que tienen las escalas geográficas que ya funcionan para la vida del planeta.

La geopolítica presenta un cierto renacimiento en los últimos años, pero bajo nuevas acepciones. La geopolítica crítica, por ejemplo, cuestiona muchas de las "huecas afirmaciones" que ha sostenido la geopolítica tradicional, asumiéndola como una imposición práctica construida históricamente sobre un mundo complejo y diverso. Su propósito es señalar como más acertado interpretar el mundo como "un mosaico de lugares vinculados y diferenciados de diversas formas" (Agnew, 2005, p. 8). Este nuevo enfoque no daría prioridad a ciertas escalas geográficas de análisis, como la global y la nacional, por su supuesta especial relevancia, sino que más bien haría hincapié en el modo en que cambian con el tiempo las relaciones entre las distintas escalas y las redes entre lugares. Este planteamiento aparta el pensamiento de los horizontes políticos que giran en torno al Estado y lo dirigen a una visión más pluralista de la organización política del pasado y del futuro. Ello tendría dos propósitos: por un lado, reflexionar y poner en práctica una política mundial que deje de estar sometida a la depredación de dicha concepción, dando una nueva estructura narrativa a la historia mundial moderna; por otro lado, sustituir la organización política por un método diferente de explicación de la geopolítica mundial, empezando a hacer una política mundial distinta (Agnew, 2005, p. 16).

La propuesta novedosa y muy sugerente de Agnew, que vienen recogiendo varios analistas como Oslender (2002, 2006), Cairo (2005) y Piazzini $(2005,2008)$, se basa en su presunción de que vivimos en un mundo en transición, en un periodo crítico que permite, en forma realista, intentar hacer un mundo menos estadocéntrico $y$, consecuentemente, menos peligroso. Esto dependerá de nuestra capacidad para escapar de las trampas mentales puestas por la imaginación geopolítica moderna y de darnos cuenta de que ella es solamente una contingencia histórico-discursiva que 
no tiene por qué seguirse sosteniendo. Esta geopolítica crítica es, pues, en palabras de Agnew (2005), "un intento de rehumanización del mundo", al situar otra vez en el centro de la geopolítica a la gente, en vez de las "fuerzas de la naturaleza", como afirmaba la geopolítica tradicional (p. XVIII). Nada más parecido a la utopía.

\section{El poder del lugar}

Siguiendo las reflexiones de esta última corriente, parecería posible sostener que si el mundo no es un “todo” orgánicamente estructurado como lo planteaba la imaginación geopolítica mundial, entonces el "lugar" gana sentido. Este, en términos de Agnew, "representa el encuentro de la gente con otra gente y con las cosas en el espacio" (citado en Cairo, 2005, p. XIV). Con esta última afirmación, Agnew se refiere a la forma en que la vida cotidiana se inscribe en el espacio y adquiere significado para grupos particulares de gente y organizaciones. Si el espacio se mantiene unido gracias a imágenes cartográficas o determinadas narrativas (a menudo oficiales), el lugar es reafirmado cotidianamente. Uno de los aportes más importantes que tiene la obra de Agnew es la reconsideración del papel del lugar en los procesos políticos y sociales: el lugar dejará de ser un escenario estático en el que los diferentes hechos se suceden y pasará a considerarse como un componente siempre dinámico de los procesos políticos, sociales y económicos (Cairo, 2005, p. XIII). Por supuesto, continúa Cairo (2005), la importancia del lugar no se deriva de ninguna "localización" especial ni de su "riqueza" en recursos, sino que es "una construcción social histórica" (Agnew, citado en Cairo, 2005, p. XIV).

Oslender (2006), por su parte, retoma también el concepto y la importancia del lugar en su estudio sobre los movimientos sociales. En ellos destaca la fuerza analítica del concepto, señalando el énfasis que permite en las subjetividades y en las formas individuales de percepción de la vida social. El lugar estaría constituido por tres elementos: la localidad, la ubicación y el sentido del lugar. El primero, la localidad, aludiría a los escenarios físicos dentro de los cuales ocurre la interacción social, pero también haría referencia a las interacciones y comunicaciones cotidianas que ahí se desarrollan; la ubicación aludiría al espacio geográfico concreto, que incluye la localidad, afectada, a su vez, por procesos económicos y políticos de escalas más amplias; finalmente, el sentido del lugar referiría el sentimiento local, por ejemplo, los sentimientos de apego que desarrollan individuos y comunidades a través de sus experiencias y memorias. Los tres no pueden ser asumidos separadamente y más 
bien actuarían como momentos fluidos cuyas interacciones se influencian y forman entre sí (Oslender, 2002, p. 7).

Así visto, parecería que el lugar sería la forma más clara y concreta de apropiación del espacio para la gente común y corriente. Con él se podría potenciar, igualmente, la construcción de espacios habitables, en el sentido profundo de habitar que retomamos de la acepción de Heidegger, cuando dice que "solo es posible habitar donde podemos construir" (citado en Cohen, 2003).

\section{Lugares y memorias}

Como ha sido puesto en evidencia por diversos autores que trabajan el tema de la memoria (Ricœur, 2003; Sánchez, 2006; Riaño, 2006; Castillejo, 2006), ella está inextricablemente atada a los lugares. Lo que los diversos ejercicios de memoria por parte de las víctimas han dejado ver en todos los procesos de reconstrucción es cómo la violencia, con todo y sus secuelas de terror, ha dejado marcados los lugares con el horror, el dolor y el sufrimiento de sus pérdidas. Diversos testimonios de pobladores que habitan zonas de violencia están inundados de referencias espaciales en sus relatos: "donde mataron a...", “aquí fue la masacre de...", "todo el pueblo quedó oliendo a muerte" y muchos otros. Todos ellos son manifestados a través de lugares y/o adverbios de lugar, que son la expresión de una serie de significaciones construidas por las poblaciones en torno a los espacios habitados y que, en los últimos años, han sido tejidas por la guerra.

Esto ha sido nombrado por Oslender (2002) como una transformación de los lugares y regiones en paisajes del miedo, con unas articulaciones espaciales específicas que rompen, de manera dramática y frecuentemente imprevisible, las relaciones sociales locales y regionales. Por sus referentes espaciales son también la expresión de lo que otros investigadores han llamado una "cartografía del terror" (Castillejo, 2006), para referirse a esos lugares que quedan marcados por las situaciones y/o eventos violentos que trae la guerra. Como lo señalaba una campesina desplazada, en referencia al lugar donde vivía y había sido afectado por la violencia:

A mí no me gusta estar aquí, ya no tenemos nada, ni somos nadie. No podemos hacer nada, solo esperar a ver si nos mandan a algún lado [...] Vivir aquí 
es como vivir en el infierno, no se respira aire puro a pesar del hecho de que vivimos en una montaña (Castillejo, 2006, pp. 174-178)

Y más adelante, narrando otra historia de horror, dice: "La finca se llama ahora purgatorio y nadie quiere trabajar allá. Si no es un purgatorio, qué mas es, sino almas en pena las que allí habitan" (Castillejo, 2006, p. 180).

Estas referencias espaciales en los relatos ponen en evidencia un asunto muy importante: la espacialidad es un componente de la memoria. Un seguimiento a estos procesos en el terreno concreto de las narrativas de la memoria ayuda a precisar el papel de esta suerte de "espacialidad" que estructura la memoria y que podríamos llamar, con Piscitelli (1998, p. 73), "recuerdos geográficos". Esto ayuda, sin duda, a esclarecer la naturaleza de ese componente espacial ligado a las experiencias de la violencia; ayuda también a esclarecer el papel que el espacio cumple en los procesos de elaboración de las memorias.

Considerar el espacio más allá de su materialidad geofísica permite, al menos en un primer registro, comprender la categoría "sentidos de lugar" como experiencia sensorial del medio ambiente y el modo como los individuos lo revisten de sentido y significado, fruto de prácticas compartidas de territorialidad, lenguaje, símbolos e historias grabadas en el paisaje (Riaño, 2006, p. 191). Ello también permite explorar cómo las memorias de la violencia han marcado esos lugares, hasta el punto de hacerlos inhabitables ${ }^{3}$. Recuperar esos lugares, resignificarlos, pasa por complicados procesos de reelaboración de los duelos que permitan a las víctimas el retorno, a través de procesos de reconstrucción del tejido social que van aparejados con la reconstrucción de los lugares, en tanto "lugares habitables". El espacio ya no estará marcado por la pérdida y el dolor, sino también por las posibilidades de habitar la vida en el presente y por las expectativas reconstruir en los lugares un futuro. Pero, en términos políticos, esta reconstrucción de los lugares ayudaría a resemantizarlos. Un esfuerzo de reconstrucción de las memorias debería dirigirse al propósito expreso de que las poblaciones puedan resignificarlos, es decir, lograr la de-construcción de

3 Procesos más recientes, como el llamado "retorno" a los lugares de donde fueron desplazados muchos campesinos por la acción de actores armados, han mostrado la dificultad, para muchos de ellos, de volver al lugar marcado por el dolor y el sufrimiento que vivieron; es decir, se ha perdido todo su sentido de comunidad para convocar "el regreso a casa". 
estas representaciones tejidas por la guerra y la re-construcción de nuevas significaciones o nuevos sentidos de lugar de los espacios habitados.

Como ya sabemos, los ejercicios de memoria tienen la posibilidad de "recuperar los lugares de la devastación" (Das, 2008, p. 158), lo que se configura como una opción de reconstruir el lazo social y la vida cotidiana. Sin duda, es preciso recuperar esos espacios para hacer habitable el presente y poder, al menos, delinear, a través de la recuperación, un cierto horizonte de futuro. Pero para lograr esta reconstrucción es preciso recordar, pues es cierto que "sin la memoria del sufrimiento el futuro deviene cada vez más frágil” (Restrepo, 2011, p. 33). ¿Cómo pueden la(s) memoria(s) del conflicto potenciar políticamente el dolor y el sufrimiento asociados a los lugares que han quedado marcados por la violencia?

Como lo ha planteado Restrepo $(2011)^{4}$ en el análisis que hace, apoyada en el teólogo alemán Jean Baptiste Metz, "el sufrimiento tiene un enorme potencial político” al que no hemos sabido darle la suficiente importancia. Retomando el concepto de memoria moral como aquella capaz de atender los gritos de dolor de las víctimas inocentes y de suscitar compasión, solidaridad y sentido de justicia (Metz, 1999, p. 181, citado en Restrepo, 2011, p. 32), esta autora se permite poner en cuestión la falta de solidaridad y de justicia, lo avaros que hemos sido en el país frente al duelo colectivo y la falta de compromiso como comunidad moral. De ahí que señale el escaso proceso de memoria que hemos hecho como nación ${ }^{5}$, mientras deja ver "la enorme fuerza política de la memoria del sufrimiento". Al mantener el recuerdo moral y al luchar contra la desaparición de la memoria, esta asume una dimensión política que no hemos sabido potenciar en Colombia, al reducir al ámbito privado el duelo personal, lo que debería ser, por el contrario, piedra de escándalo colectivo y duelo público (Restrepo, 2011, p. 35).

La propuesta que queremos hacer con estas reflexiones es la de articular la potencia del lugar que deja ver la geopolítica crítica hoy y la enorme fuerza política del dolor y el sufrimiento, para hacer de ellos un instrumento de lucha política que permita no solo el reconocimiento de la guerra que han vivido y de su situación de víctimas,

4 El artículo fue publicado inicialmente por el periódico El Colombiano en el 2000 y fue reeditado recientemente en la revista Desde la Región, 54., por su vigencia y pertinencia en el momento actual.

5 Sin duda, tiene razón al señalar que nuestra memoria de las víctimas es tan pobre que de ella tenemos, en muchos casos, solo las estadísticas (Restrepo, 2001, p. 33). 
sino también la posibilidad de recuperar la vida y la dignidad. La apuesta no es, pues, por una memoria oficial convertida en historia, que "sería muda e impotente frente al sufrimiento" (Metz, citado en Restrepo, 2011), sino por una pluralidad de memorias subjetivas, "huellas de la experiencia vivida" (Sánchez, 2006, p. 22), tejidas con los recuerdos dolorosos de los lugares donde ha vivido la guerra.

Si se desarrollan y se ponen en público estas memorias, aunque ellas sean más íntimas, familiares, vecinales, cotidianas, se estarán reemplazando "los espacios de poder por el poder de los espacios” (Piazzini et al., 2006) ${ }^{6}$. Con ello, el reconocimiento, la dignidad y el lugar de las víctimas en la memoria colectiva de la sociedad no dependerán del espacio que les conceda el Estado (léase: la memoria oficial), sino de los microespacios donde se desarrolla la vida cotidiana. Y es en este ámbito donde ella tiene sentido, significación y posibilidades de agencia, pues, como acertadamente señala Heller (1998), “para la mayoría de los hombres la vida cotidiana es la vida”.

\section{Referencias}

Agnew, J. (2005). Geo-política: una revisión de la política mundial. Madrid: Trama.

Blair, E. (2011a). Memoria y poder. (Des)centrar el poder del Estado y (des)estatalizar las memorias. En Universitas Humanística, 72. Bogotá: Universidad Javeriana.

Blair, E. (2011b). Micropolíticas de las memorias: el sentido político de la dignidad. Desde la Región, 54, (19-30). Medellín: Corporación Región.

Blair, E., Pimienta, A. y Agudelo, C. (2004). Conflicto armado, actores y territorios: los visos de un caleidoscopio. Medellín: INER.

Blair, E. et al. (2009). De memorias y de guerras (informe final de investigación). Medellín: INER.

Bolívar, I. (2006). Espacio, poder y violencia: la autocomprensión de la sociedad burguesa. En D. Herrera y E. Piazzini (Eds.). (Des)territorialidades y (no) lugares. Procesos de configuración y transformación social del espacio (pp. 117-133). Medellín: Universidad de Antioquia.

6 Es, en efecto, un juego de palabras que va mucho más allá y descentra el problema del poder de la esfera exclusiva del Estado. Para una amplia reflexión sobre estos "otros" espacios de poder, no necesariamente estatales, ver Agnew (2005) y Piazzini et al. (2008). 
Cairo Carou, H. (2005). Repensando la geo-política: la renovación de la disciplina y las aportaciones de John A. Agnew (Prólogo). En Geo-política: una revisión de la política mundial. Madrid: Trama.

Carrizosa, C. (2010). Nuevas ciudadanías y configuración de sujetos políticos a partir del conflicto armado. La experiencia de la Asociación de Víctimas de Granada, Antioquia (Asovida) (tesis de grado). Medellín: Universidad de Antioquia, Departamento de Antropología.

Castillejo, A. (2006). Voces desde el sepulcro: terror, espacio y alteridad en la guerra colombiana. En Herrera, D. y Piazzini, E. (Eds.). (Des)territorialidades y (no) lugares. Procesos de configuración y transformación social del espacio (pp. 173-183). Medellín: Universidad de Antioquia.

Cohen, E. (2003). Volver del campo de concentración: testimoniar ante el enmudecimiento de la lengua. Metapolítica: Las Barbaries de la Civilización, 28, 47-55. México: Cepcom.

Das, V. (2008). Trauma y testimonio. En Ortega, F. (Ed). Veena Das. Agentes de dolor, sujetos de dignidad (pp. 145-169). Bogotá: Universidad Nacional de Colombia.

Foucault, M. (1999). La verdad y las formas jurídicas. En Estrategias de poder. Obras esenciales (pp. 169-282, vol. II). Barcelona: Paidós.

Heller, Á. (1998). Sociología de la vida cotidiana. Barcelona: Península.

Oslender, U. (2002). Espacio-lugar y movimientos sociales: hacia una espacialidad de resistencia. Scripta Nova, Revista Electrónica de Geografía y Ciencias Sociales, 15(3). Universidad de Barcelona.

Oslender, U. (2006). Des-territorialización y desplazamiento forzado en el Pacífico colombiano: la construcción de geografías del terror. En Herrera, D. y Piazzini, E. (Eds.). (Des)territorialidades y (no) lugares. Procesos de configuración y transformación social del espacio (pp. 155-172). Medellín: Universidad de Antioquia.

Piazzini, E. (2006). El tiempo situado: las temporalidades después del "giro espacial”. En Herrera, D. y Piazzini , E. (Eds.). (Des)territorialidades y (no) lugares. Procesos de configuración y transformación social del espacio (pp. 53-73). Medellín: Universidad de Antioquia. 
Piscitelli, A. (1998). Pasión, casamiento y poder: tradición oral y memoria en familias latifundistas del café (Minas Gerais, Brasil). En Lulle, T., Vargas, P. y Zamudio, L. (Eds.). Los usos de la historia de vida en las ciencias sociales I (pp. 65-81). Colombia: Anthropos.

Restrepo, B. (2011). Justicia a los muertos o un alegato a favor del recuerdo moral. Desde la Región, 54, 31-36). Medellín: Corporación Región.

Reyes, M. (2003). Por los campos de exterminio. Barcelona: Anthropos.

Riaño, P. (2006). Geografías del desplazamiento. Territorialidades y movilidades urbanas. En Herrera, D. y Piazzini, E. (Eds.). (Des)territorialidades y (no) lugares. Procesos de configuración y transformación social del espacio (pp. 185-201). Medellín: Universidad de Antioquia.

Ricœur, P. (2003). La memoria, la historia, el olvido. Madrid: Trotta.

Ricœur, P. (2004). Tiempo y narración I. México: Siglo XXI.

Sánchez, G. (2006). Guerra, memoria e historia (2. a ed.). Medellín: La Carreta. 